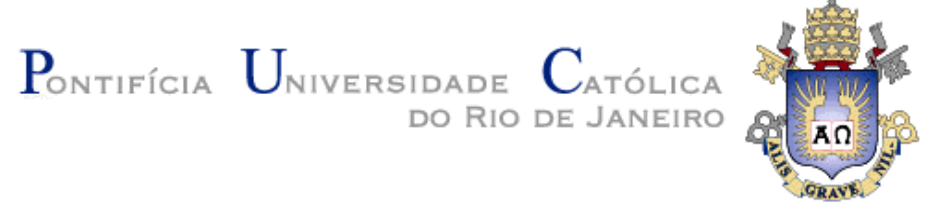

Rafael Antônio Pinto Pena

Suporte semântico à publicação de conteúdo jornalístico na Web

Dissertação de Mestrado

Dissertação apresentada como requisito parcial para a obtenção do grau de Mestre pelo Programa de Pós-graduação em Informática do Departamento de Informática do Centro Técnico e Científico da PUCRio.

Orientador: Prof. Daniel Schwabe 


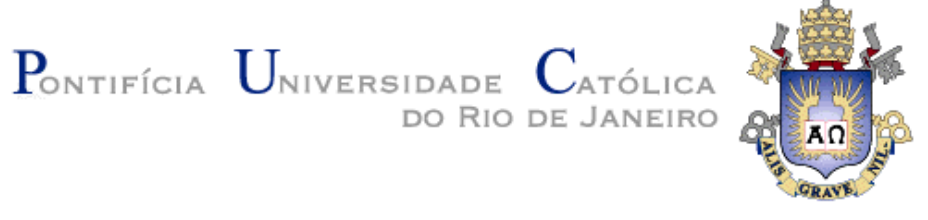

Rafael Antônio Pinto Pena

\section{Suporte semântico à publicação de conteúdo jornalístico na Web}

Dissertação apresentada como requisito parcial para a obtenção do grau de Mestre pelo Programa de Pósgraduação em Informática do Departamento de Informática do Centro Técnico e Científico da PUC-Rio. Aprovada pela Comissão Examinadora abaixo assinada.

Prof. Daniel Schwabe

Orientador e Presidente

Departamento de informática - PUC-Rio

Prof. Edward Hermann Haeusler Departamento de informática - PUC-Rio

Prof. Giancarlo Guizzardi Departamento de informática - UFES

Prof. José Eugenio Leal Coordenador Setorial do Centro

Técnico Científico - PUC-Rio

Rio de Janeiro, 07 de Fevereiro de 2012 
Todos os direitos reservados. É proibida a reprodução total ou parcial do trabalho sem autorização da universidade, do autor e do orientador.

\section{Rafael Antônio Pinto Pena}

Graduou-se em Tecnólogo em Processamento e Dados pela Pontifícia Universidade Católica do Rio de Janeiro (PUCRJ) em Dezembro de 1999. Tem experiência na área de Ciência da Computação, com ênfase em Desenvolvimento de Software. Tem trabalhado em análise de sistemas desde 1997. Mais especificamente com Desenvolvimento de Sistemas para Web, e recentemente, Desenvolvimento de Produtos Jornalísticos para Web.

Ficha Catalográfica

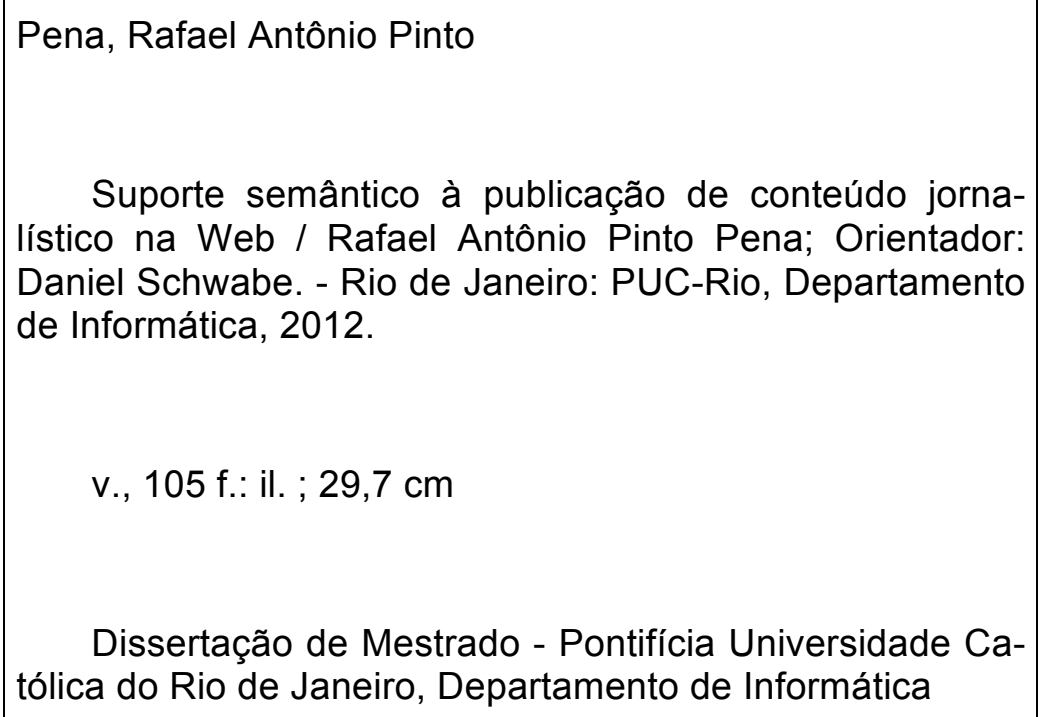

Suporte semântico à publicação de conteúdo jornalístico na Web / Rafael Antônio Pinto Pena; Orientador: Daniel Schwabe. - Rio de Janeiro: PUC-Rio, Departamento de Informática, 2012.

v., 105 f.: il. ; $29,7 \mathrm{~cm}$

Dissertação de Mestrado - Pontifícia Universidade Católica do Rio de Janeiro, Departamento de Informática

Referencias bibliográficas incluídas.

Web Semântica; Modelo de Domínio; Conteúdo Jornalístico; Conteúdo Web; Empresas Jornalísticas; Mídia Digital 


\section{Agradecimentos}

A Deus pela maravilhosa forma de vida que me foi concedida.

A minha esposa Carolyna Maciel pelo apoio, amor, compreensão e por estar ao meu lado em todos os momentos me tranquilizando e fazendo acreditar que seria possível.

Aos meus pais, Fernando Pena e Nina Pena, pela educação, carinho, amor e por me mostrarem a importância do aprendizado e do trabalho.

As minhas irmãs Catarina Pena e Fabiana Pena Ruiz pelo amor, pelos exemplos e ensinamentos.

A minha avó Griselda Schleder, por lutar contra a doença para permanecer viva até ver seus netos formados. Uma inesquecível demonstração de amor e de valorização do estudo.

Ao meu orientador Professor Daniel Schwabe, pelo enorme apoio, confiança e orientação.

Ao Professor Giancarlo Guizzardi pela grande ajuda na modelagem conceitual.

Ao amigo Janilton Maciel pela enorme ajuda no desenvolvimento do protótipo.

Aos amigos da Globo.com, Davidson Fellipe, Franklin Amorim, Claudio Braga, Paulo Ricardo Muniz, Camila Dias, Newton Fleury e Alexandre Moreno por sempre me apoiarem e colaborarem com ideias e melhorias.

Sou grato aos jornalistas que participaram da pesquisa e tanto ajudaram neste trabalho. André Amaral, Gustavo Poli, Bernardo Ferreira, Bernardo Pombo, Eduardo Orgler e Rodrigo Breves.

À Globo.com, pelo financiamento e auxílios concedidos, sem os quais este trabalho não poderia ter sido realizado. Em especial ao Juarez Queiroz por conseguir este benefício para os funcionários e ao Jacques Douglas Varaschim por todo apoio.

Aos professores da Comissão examinadora. 


\section{Resumo}

Pena, Rafael Antônio Pinto; Schwabe, Daniel. Suporte semântico à publicação de conteúdo jornalístico na Web. Rio de Janeiro, 2012. 105p. Dissertação de Mestrado - Departamento de Informática, Pontifícia Universidade Católica do Rio de Janeiro.

O consumo de conteúdo jornalístico na Web aumenta a cada dia. No entanto, boa parte desse conteúdo ainda é produzido segundo paradigmas da mídia impressa. Paralelamente a isto, a Web Semântica ou Web 3.0, adiciona uma camada de "inteligência" à Web, onde computadores são capazes de extrair significados dos conteúdos acessados na Web, e consequentemente, processá-los. Neste trabalho foi definido e testado um modelo de publicação de conteúdo jornalístico apoiado pela Web Semântica. Foi desenvolvida uma ferramenta de apoio para produtores de conteúdo, com o objetivo de melhorar o processo de construção de narrativas jornalísticas para web, através da sugestão de padrões narrativos e de informações objetivas que dão suporte ao tipo de narrativa desejado. Um estudo de caso foi realizado para avaliar em ambiente real o modelo proposto. Um grupo de jornalistas usou a ferramenta desenvolvida, com aceitação unânime.

\section{Palavras-chave}

Web Semântica; Modelo de Domínio; Conteúdo Jornalístico; Conteúdo Web; Empresas Jornalísticas; Mídia Digital. 


\section{Abstract}

Pena, Rafael Antônio Pinto; Schwabe, Daniel (Advisor). Semantic Support for the publication of news content on the Web. Rio de Janeiro, 2012. 105p. MSc Dissertation - Departamento de Informática, Pontifícia Universidade Católica do Rio de Janeiro.

The use of journalistic content on the web increases every day. However, much of the content is still produced according to the paradigms of print media. Parallel to this, the Semantic Web or Web 3.0, adds a layer of "intelligence" to the Web, where computers are able to extract meaning from the visited web content, and consequently, process them. This work defined and tested a model of publishing news content supported by the Semantic Web. It was developed a support tool for content producers, in order to improve the process of construction of news stories for the web, using the suggestion of narrative patterns and objective information that support the desired type of narrative. A case study was conducted to evaluate the proposed model in a real environment. A group of journalists used the developed tool, with unanimous acceptance.

\section{Keywords}

Semantic Web; Domain Model; Journalistic Content; Web Content; Media Companies; Digital Media. 


\section{Sumário}

1 Introdução

2 Fundamentos e estado da arte 14

2.1 Fundamentos 14

2.1.1 Web Semântica e Linked Open Data 14

2.1.2 Sistema de frames e slots 20

2.1.3 UFO (Unified Foundational Ontology) 22

2.2 Estado da arte 32

2.2.1 Utilização de dados semânticos em empresas de mídia 32

$\begin{array}{ll}\text { 2.2.2 Modelos de estruturas narrativas } & 37\end{array}$

3 Modelo de publicação de conteúdo jornalístico na web 39

3.1 Descrição do contexto de uso 39

3.2 Descrição do fluxo desejado 41

4 Modelos de ontologias $\quad 45$

4.1 Descrição da metodologia de modelagem usada 45

4.1.1 Construção de um modelo de jogo de futebol 46

4.1.2 Definição dos estereótipos e esquemas narrativos 48

4.2 Ontologia do Futebol 51

4.2.1 Fragmento das participações em um jogo 52

4.2.2 Fragmento das etapas de disputa de um jogo 54

4.2.3 Fragmento do lance de disputa comum 55

4.2.4 Fragmento do lance de jogo individual 58

4.2.5 Fragmento dos Lances Complexos 61

4.2.5.1 Lances faltosos 61

4.2.5.2 Lances de jogo 63

4.2.6 Resumo do modelo 66

4.3 Modelo de estereótipos e narrativas 68

4.3.1 Regras de detecção de estereótipos 68 
5 Estudo de caso $\quad 80$

5.1 Protótipo funcional 80

$\begin{array}{ll}5.1 .1 \text { Interface de autoria de matéria } & 80\end{array}$

5.1.2 Exemplos de templates de estereótipos 85

$\begin{array}{ll}5.2 \text { A experiência de uso } & 91\end{array}$

5.2.1 Indicadores sobre a utilização do protótipo 92

5.2.2 Pesquisa de opinião sobre o uso do protótipo 96

6 Conclusões e próximos passos 98

6.1 Conclusões 98

$\begin{array}{ll}6.2 \text { Próximos passos } & 100\end{array}$

6.2.1 Oportunidades relacionadas ao modelo de publicação 100

6.2.2 Oportunidades relacionadas aos esquemas narrativos 101

7 Referências bibliográficas 103 


\section{Lista de imagens}

Figura 1 - Quadrado de Aristóteles. Figura extraída de [Guizzardi et al, 2009]

Figura 2 - Fragmento da UFO-B. Objetos e Eventos. Figura extraída de [Guizzardi et al, 2008]

Figura 3 - Fragmento da UFO-B: Relações de Allen. Figura

extraída de [Guizzardi et al, 2008]

Figura 4 - Fragmento da Ontologia de Processo de Software de ODE. Extraída de [Guizzardi et al, 2008]

Figura 5 - Fragmento Remodelado da Ontologia de Processo de Software (Substanciais). Extraída de [Guizzardi et al, 2008]

Figura 6 - Fragmento Remodelado da Ontologia de Processo de Software (Eventos). Extraída de [Guizzardi et al, 2008]

Figura 7 - Extrato da ontologia de fundamentação. Extraída de [Almeida et al, 2008]

Figura 9 - Esquema simplificado do processo de publicação de conteúdo web existente

Figura 10 - Esquema simplificado do processo de publicação de conteúdo web proposto no trabalho

Figura 11 - Fragmento das participações em um jogo

Figura 12 - Fragmento das participações em um jogo alinhado com a UFO

Figura 13 - Fragmento das etapas de disputa de um jogo

Figura 14 - Fragmento das etapas de disputa de um jogo alinhado com a UFO

Figura 15 - Fragmento do lance de disputa comum

Figura 16 - Fragmento do lance de disputa comum alinhado com a UFO 
Figura 17 - Fragmento do lance de jogo individual

Figura 18 - Fragmento do lance de jogo individual alinhado com a UFO 61

Figura 19 - Fragmento do lances faltosos 62

Figura 20 - Fragmento dos lances faltosos alinhado com a UFO 63

Figura 21 - Fragmento do lances válidos 64

Figura 22 - Fragmento dos lances válidos alinhado com a UFO 66

Figura 23 - Matriz de estereótipos 68

Figura 24 - Interface de autoria de matérias 82

Figura 25 - Interface para seleção de jogo para crônica 83

Figura 26 - Interface de sugestão de estereótipos 84

Figura 27 - Interface de autoria de matéria com template de estereótipo selecionado $\quad 85$

Figura 28 - Template narrativo para estereótipo de jogo movimentado 86

Figura 29 - Template narrativo para estereótipo de jogo morno 86

Figura 30 - Template narrativo para estereótipo de goleada $\quad 87$

Figura 31 - Template narrativo para estereótipo de placar duvidoso $\quad 88$

Figura 32 - Trecho de matéria feita com template Goleada 88

Figura 33 - Trecho de matéria feita com template Placar Duvidoso $\quad 89$

Figura 34 - Trecho de matéria feita com template Artilheiro 90

Figura 35 - Gráfico comparativo entre quantidade de matérias produzidas e quantidade de matérias produzidas com templates narrativos do protótipo

Figura 36 - Gráfico comparativo entre quantidade de jogos e a quantidade de jogos para os quais pelo menos uma matéria foi produzida com template narrativo do protótipo

Figura 37 - Gráfico com as quantidades de uso dos templates narrativos do protótipo 


\section{Lista de Tabelas}

Tabela 1 - Estereótipo Jogo Movimentado 69

Tabela 2 - Estereótipo Jogo Morno 70

Tabela 3 - Estereótipo Jogo Truncado $\quad 71$

$\begin{array}{ll}\text { Tabela } 4 \text { - Estereótipo Goleada } & 71\end{array}$

Tabela 5 - Estereótipo Jogo Recorde no campeonato 72

Tabela 6 - Estereótipo Placar Duvidoso 73

Tabela 7 - Estereótipo Melhor Performande do Jogo 75

Tabela 8 - Template narrativo Jogo Movimentado / Jogo Morno 75

Tabela 9 - Template narrativo Goleada 76

Tabela 10 - Template narrativo Jogo Truncado 77

Tabela 11 - Template narrativo Placar Duvidoso 77

Tabela 12 - Template narrativo Primeiro no ranking do campeonato 78

Tabela 13 - Template narrativo Atleta em Destaque 79

Tabela 14 - Resultado da pesquisa de opinião feitas com os

$\begin{array}{ll}\text { jornalistas envolvidos } & 97\end{array}$ 